\title{
Transient Process at Atmospheric Discharge into the Landline and the Appearance of an Electric Arc in the Switch
}

\author{
Slobodan N. Bjelić \\ Faculty of Technical Sciences, Kosovska Mitrovica, Serbia \\ E-mail: slobodanbjelic49@yahoo.com \\ Filip N. Marković \\ Faculty of Technical Sciences, Kosovska Mitrovica, Serbia \\ E-mail: ridjikm@gmail.com
}

\author{
Nenad A. Marković \\ Kosovo and Metohija Academy of Applied Studies, Department Urosevac - Leposavic, Serbia \\ E-mail: nen.mark74@yahoo.com
}

Received: 02 January 2021; Accepted: 25 February 2021; Published: 08 April 2021

\begin{abstract}
This document proposes a model of the process of atmospheric discharge of overhead lines followed by an electric arc. The intensity of atmospheric discharges, followed by electric arc and destruction, is determined by the difference in potential and current. Such a structure and form of discharge make it difficult to analyze the transient process and obtain adequate solutions. That is why the model of the transient process in the electric arc of the switch under the conditions of interruption of the AC circuit is specially analyzed. Simple equivalent schemes for the analysis of phenomena with given values of linear parameters are presented, which are very simple to apply. All influential parameters by which the overvoltage values in the model can be estimated were also taken into account. The evaluation of the proposed model was performed using the adapted MATLAB program psbsurlightcuurent for atmospheric electrical discharge, which contains a high frequency current source. The verified simulation method was used to verify the results as part of a method derived from artificial intelligence algorithms. The process simulation program, the obtained voltage and current diagrams confirm the application of the simulation algorithm model.
\end{abstract}

Index Terms: Algorithm, atmospheric discharge, electric arc, transient process.

\section{Introduction}

In the XX century, many theories emerged about the occurrence of storms, the mode of their discharge, but not all of them were sufficient to explain the mode of action of leaders and streamers (light) for ionization in the atmosphere.

The cloud was thought to be the conducting medium of positive and negative charges, and the discharges were accompanied by shocks and the emergence of 'leader=tree' and 'streamer=branches' that formed charge with two effects: lightning-lightning and sound-thunder [1,2].

The process model was like the electrostatic one [1]:

a) capacitor with conductive cover of two adjacent clouds or clouds and ground,

b) light effects create the movement of charge through the leader at speed $c=3 \cdot 10^{8} \mathrm{~m} / \mathrm{s}$,

c) parameters are their own inductance and capacitance, and duration is their consequence.

That theory has been completely rejected today for the following reasons:

- air can be more or less conductive if it accidentally finds ions and electrons,

- in the chemical sense, the cloud is an insulator, water molecules bind free ions in the atmosphere,

- the drops move under the influence of gravity and electrical forces and carry loads in the cloud,

- drops have real masses and ionization is gradually expanding, cloud discharge is slow and differs from rapid discharge and overvoltage in the electrostatic model of the conductor lining capacitor. 
Discharge is an electromagnetic, high-frequency phenomeno whose effects are shocks and surges, resulting from [3]:

- rapid changes in the potential gradient near the ground,

- the direct impact of the discharge leader into conductors or parts of electrical equipment.

On electrical systems in urban and rural areas they are registered $[4,5,6]$ :

- direct impact on an object (an impact on an air conduit, which is a source of power because a wave enters the building through the conduit)),

- indirect impact near the object (the impact near the water-excessive currents and surges are transmitted to the network and impact in the indirect impact near the building-the potential of the earth around the impact point increases and is dangerous to the object-equipment).

The processes in the circuit breaker arc are affected by two different types of over voltages: commutation and atmospheric and they can change in a wide range, where atmospheric discharges can create over voltages of the order of MV. These over voltages jeopardize the operation of the circuit breaker and must be limited, as breakdowns in the space between the contacts create currents that have short-circuit current levels. In this regard, closely spaced non-shortcircuit valve arresters can be used. Research in the world shows that the peak of lider has very high potential $(1-20$ MV), and it can create the current of $5-100 \mathrm{kA}$, and similar results are presented on diagrams made in this paper.

Therefore, in this paper, a model was formed using a mathematical procedure, from which solutions are obtained sufficiently accurate values of atmospheric discharges.

Possible problem research methods are analytical methods, numerical programming, support approaches, algorithms based on artificial intelligence, graphical testing of algorithm, partially obtained algorithms and tabularly investigated algorithms.

The advantage of formed model and proposed MATLAB simulation is a large number of possibilities, and simulation results are shapes and characteristic values of obtained wave diagrams. In the package of MATLAB simulation programs, through the change of the switch position for the selected load parameters, the verification of the transient state model was performed. All voltage waveforms are shown in the diagrams.

The paper is organized as follows: Section 2 provides an overview of the literature related to atmospheric discharge. Section 3 presents a model of the transient process with derived equations for the calculation of the voltage and currents of the electric arc. A theoretical analysis of the model performed using the original symbolic-complex method is given in Section 4. In Section 5, the simulation results are analyzed and the proposed model of the transient process is discussed. Finally, some concluding considerations are presented in Section 6.

\section{Related Work}

Dealing with the effects of atmospheric discharges is not a new phenomenon. Many studies have been conducted on this topic and many papers have addressed this issue $[2,7,8]$.

Back in the 80 's, the problem of atmospheric emptying was addressed by Magono [9], who suggested that the problem be approached from a computer side, because he concluded that much faster and simpler solutions were obtained.

An analysis of the transient process requires an electric field model and the coupling potentials of conducting parts and charges. Discharges have a stochastic character and the accuracy of analytical formulas can be evaluated by experiment or using artificial intelligence-simulation methods, of N. Marković et al. [6,10].

In the view of S. Bjelić and others [7,8,9], the phenomenon of discharge generates overvoltages on conductive elements, lines and loads, which are described by differential equations. In addition to the effect of overvoltage, the discharge acts on the conductor much like a low frequency current through thermal and electrodynamic effects. Discharge also acts in channels (leader/streamer) by increasing the country's potential in the surrounding area, and creates a voltage of steps when human injuries are possible.

Electrical networks are low-frequency and result is current propagation of voltage waves of atmospheric over voltages in relation to this frequency. Lightning is a high-frequency phenomenon (of $\mathrm{kHz}$ to $\mathrm{MHz}$ order): an atmospheric wave propagates along water at a certain speed depending on the frequency of its occurrence. The change in the physical environment creates the phenomenon of propagation and/or reflection of waves whose frequency depends on the differences in impedance between the media. The frequency of the progressive wave depends on the steep growth of the pulse in relation to the time and length of the medium.

Models of the phenomenon applied to lightning strikes in laboratory tests have shown that a load powered by a 30 $\mathrm{m}$ cable of shielded SPD (surge protection) withstands a maximum reflected voltage of $2 V_{P}$, S. Bjelić concludes at the end of presentation. 


\section{Model of the Transition Process in the Electrical Circle of the Switch}

The above brief review of works and explanations of the electric arc shows that, regardless of the large volume of collected theoretical and experimental work, and the whole series of achieved results, the question of processes taking place in the arc and its extinguishing in switches requires further research. More accurate calculation methods must consider the volt-ampere characteristics of the arc and other parameters such as the dependence of the process in the electric arc on thermal conductivity, thermal capacitance, electron gas density between contacts and temperature, etc.

In this research, authors start from an assumption that:

- The static characteristic of the arc in the switch corresponds to the stationary and quasi-stationary state when the resistance of the arc is constant, while the dynamic characteristic is determined by the conditions of heat transfer from the arc column [11].

- Theory/experiment can define the process if the gradient function with respect to the arc length is determined $E=f\left(I_{\ell}\right)$.

The dynamic theory of ionization and electric arc is defined by the models of M. Kassi and O. Mary [12].

M. Kassi: In the arc model, electrical conductivity and heat dissipation are constants. Assuming that the current density and the field gradient are constant (steady state), the arc cross-sectional area depends on the current and time. The static volt-ampere characteristic does not depend on the current density and amounts [13,14,15]:

$$
P_{0}=E^{2} / \rho_{r}, \vec{E}=\sqrt{\rho_{r} P_{0}}
$$

Where $\rho_{r}$ is the specific resistance, $P_{0}$ is the power by unit of volume.

O. Mary: The assumption is that the radius of the channel of the arc is a constant and that the temperature changes along the radius. The model provides a solution for the dynamic volt-ampere characteristic, and the parameters of the arc resistance are: thermal time constant $T_{\theta \text {.arc }}$ and added power $P_{0}$ from volume unit $[13,14,15]$.

Voltage-potential $v(x, t)=\varphi(x, t)$ and current $i(x, t)$ the points in $x$ the telegraph equations of Thompson are:

$$
\frac{\partial i_{\text {leader }}(x, t)}{\partial x}=-\frac{\partial q(x, t)}{\partial t}=-C \cdot \frac{\partial \varphi(x, t)}{\partial t}
$$

Temporal change-electrify $q(x, t)$ by longitudinal channel capacitance is currents:

$$
\frac{\partial v(x, t)}{\partial x}=-E(x, t)-\frac{i(x, t)}{G(x, t)}
$$

If its $E$ potential gradient, $l$ length of arc, $C$ longitudinal capacitance, leader/streamer voltage is:

$$
v_{l, s}(x, t)=\int_{0}^{\ell}-E d x=-E \cdot l
$$

The processes involved in establishing the voltage at the circuit breakers are analyzed under the conditions of the circuit breaker. When the current goes through zero, the switch has a source voltage if it goes from conductive to nonconductive. If the initial current is zero, the process is analyzed according to the scheme in Fig. 1.a,b.

The sum of currents in a circuit (arc, resistance and capacitance) is equal to:

$$
i_{\Sigma}=i_{\text {arc }}+i_{C}
$$




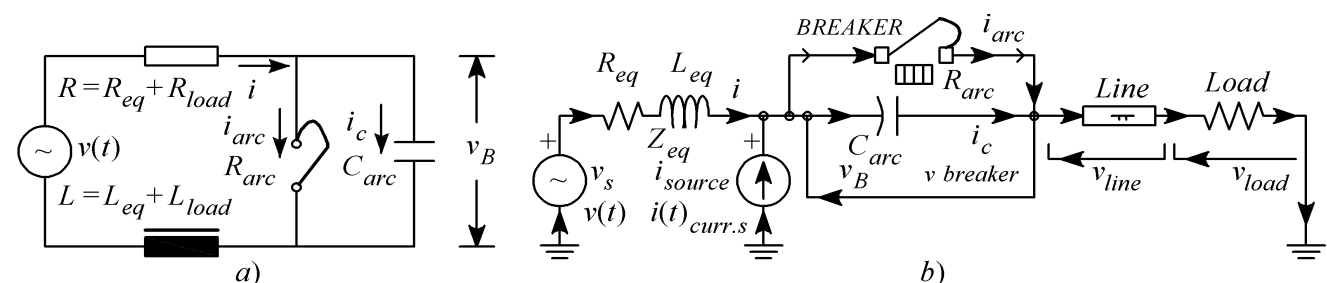

Fig.1. a) Process analysis circuit, b) Simulation scheme.

Change of arc voltage (on capacitor $C_{S}$ ) creates a capacitive current that equals:

$$
i_{C}=C_{s}\left(d v_{c} / d t\right) \rightarrow v_{C}=v_{l}=v_{p}
$$

To investigate voltage diagrams- $V_{a}$, G. Aerton [10] has suggested an empirical formula:

$$
V_{a}=a+b \ell+(c+d \cdot \ell) / I
$$

Where $a, b, c, d$ is the constant,

$V_{a}$ is the voltage,

$\ell$ is the length,

$I_{a}$ is the arc current.

The inductive component of the electric field can be neglected because it is comparable to the electric $\left(10^{3} \mathrm{~V} / \mathrm{cm}\right)$ only for fast currents which are $10^{10} \mathrm{~A} / \mathrm{s}[16,17]$ :

$$
Z_{\text {load }}=R=V_{n}^{2} / P
$$

The voltage in this case has two components:

1. forced industrial frequency voltage represents the source voltage, ie. the voltage acting on the system-grid and currently being established on the switching elements after the circuit is interrupted,

2. free voltage components determined by the character of the transient established voltage process. The free component is superposed to the forced one if the process has an oscillatory character [18].

All methods of calculating arc voltage assume that the influence of the switching elements is neglected. The contour currents method and the superposition of the inverse current's superposition method are used to calculate the values $v_{B}$.

The first method is based on the application of the Kirhof rule. For the circuit diagram (condition of interruption of the current in the switch) the contour equation is made, and the voltage is determined $v_{B}$ which depends on the parameters and argument:

$$
v_{B}^{n} / d t^{n}+a_{1} d^{n-1} v_{B} / d t^{n-1}+\ldots \ldots . a_{n} v_{B}=f(t)
$$

The solution to this equation has two components:

$$
v_{B}(t)=v_{\text {forced }}(t)+v_{\text {free }}(t)
$$

$v_{\text {forced }}(t)$ is a partial solution of equation (10) for steady state in a circuit. If the circuit is a source with $50 \mathrm{~Hz}$, $v_{\text {forced }}(t)$ is the return voltage with $50 \mathrm{~Hz}$. Free component $v_{\text {frees }}(t)$ is a general solution of equation (10):

$$
v_{\text {free }}(t)=A_{1} e^{r 1 t}+A_{2} e^{r 2 t}+\ldots \ldots A_{n} e^{r n t}
$$

Where $A_{1}, \ldots A_{n}$ is the integration constants, $r_{1}, \ldots r_{n}$ is the roots of the characteristic equation corresponding to equation (10). 
If the contour current method is combined with the operator; then, when transitioning from the time domain to the complex domain, the initial conditions are important and the free component of the voltage can be determined $v_{B}$ :

$$
v_{\text {free }}(p)=A_{1}(p) / A_{2}(p)
$$

By the second method, ie. method of superposition, the process in the circuit at the point where the impact is positioned is added a power source with electricity. Voltage setting occurs under asymmetry conditions, especially in three-phase circuits when the current in three phases cannot pass simultaneously at zero-the switch is interrupted in one phase and continues to flow through the other two phases. Asymmetric conditions are then created to establish a voltage on the first off switch circuit.

For voltage measurement $v_{B}$ experimental and proven simulation methods developed in a software package are used (MATHLAB, Matematica Volfram, etc). For the calculation, a good method of symmetric components is based on three symmetric systems: direct, inverse, and zero-order systems [18].

In this case, the scheme in Fig. 1.a for which according to equation (9) can be written [16]:

$$
\begin{aligned}
& v_{0}(t)=i R+L(d i / d t)+v_{B} \\
& i=i_{\text {arc }}+i_{c} \quad i_{c}=C \frac{d u_{p}}{d t} \quad i_{\text {arc }}=\frac{v_{B}}{R_{\text {arc }}}
\end{aligned}
$$

Where $v(t)$ is the source voltage, $R, L$ is the resistance and burden of inductance and captures the equivalent network impedance $Z_{e q}$, Fig. 1.b.

The role of resistance $R$ is small and at first approximation can be neglected. The first equation of expression (13) can be solved by voltage $v_{B}$ :

$$
L C \frac{d^{2} v_{B}}{d t^{2}}+\frac{L}{R_{a r c}} \frac{d v_{B}}{d t}+\left(1-\frac{L}{R_{a r c}^{2}} \frac{d R_{a r c}}{d t}\right) \cdot v_{B}=v_{0}(t)
$$

or:

$$
A \frac{d^{2} x}{d t^{2}}+B \frac{d x}{d t}+C x=A \cdot f(t)
$$

The characteristic quadratic equation is obtained $A r^{2}+B r+C=0$, with the solution by variable $r$ $r_{1,2}=k_{1,2}=-\frac{B}{2 A} \pm \sqrt{\frac{B^{2}}{4 A^{2}}-\frac{C}{A}}=-a \pm m$ and constants $C_{1}, C_{2}$, where is the value for $x$ :

$$
\begin{aligned}
& x=e^{-a t}\left\{C_{1} e^{-m t}+C_{2} e^{m t}+\right. \\
& +\left\{\frac{1}{2 m}\left(e^{m t} \int e^{-k 1 \cdot t} f(t) d t-e^{-m t} \int e^{-k 2 \cdot t} f(t) d t\right)\right\}
\end{aligned}
$$

By examining the previous functions, the influence of the circuit elements on the voltage is determined $v_{B}$. Capacitor $C$ is statically loaded from a current source via inductance $L$ and resistance $R$ which dampens the process $[12,16]$.

\section{Theoretical Model of Emission Followed by Electric Arc}

Atmospheric discharge represented by a source of high frequency current $(\mathrm{MHz})$ and load, make it impossible to apply the Laplas-Karson operator account method. Therefore, the analysis was performed using a theoretically original symbolic-complex method and an equation for voltages and currents in place $x$ from the input to the line with distributed parameters ( $r, l, g=0, c-$ from the input to the line with distributed parameters), Fig. 2. 
For selected voltage directions $(v, v-(\partial v / \partial x) d x)$ and current $(i, i-(\partial i / \partial x) d x, \partial i / \partial x), i(\ell, t)$, Fig. 2.a, we can write:

$$
\begin{aligned}
& -\partial v / \partial x=r \cdot i+l_{l}(\partial i / \partial t) \\
& -\partial i / \partial x=g \cdot v+c(\partial v / \partial t)
\end{aligned}
$$

Boundary conditions for $t=0$ and $t=T$ are:

$$
\begin{aligned}
& v(x, t)=v(x, 0) \quad i(x, t)=i(x, 0) \quad i_{1}\left(x_{1}, t\right) \Leftrightarrow \widehat{I}_{1} \\
& v(x, t)=v(x, T) \quad i(x, t)=i(x, T) \quad i_{2}\left(x_{2}, t\right) \Leftrightarrow \widehat{I}_{2}
\end{aligned}
$$

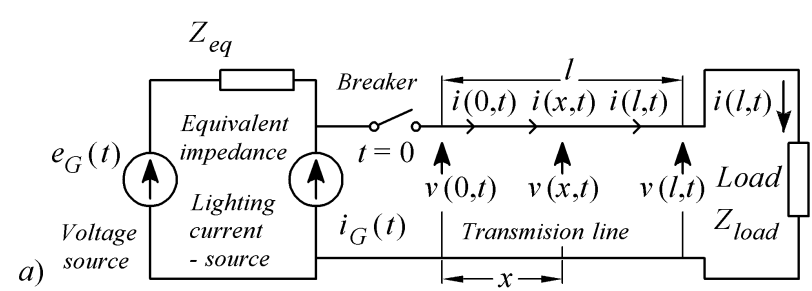

b)

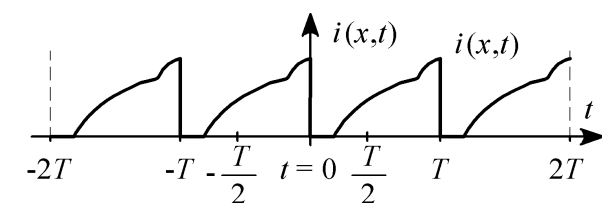

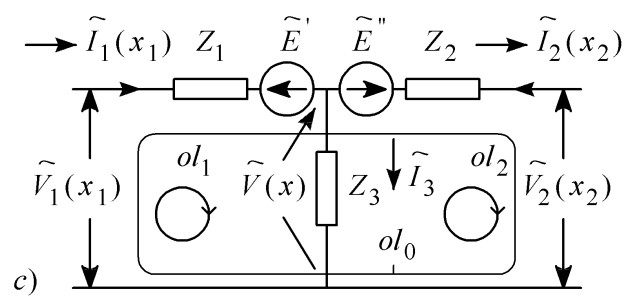

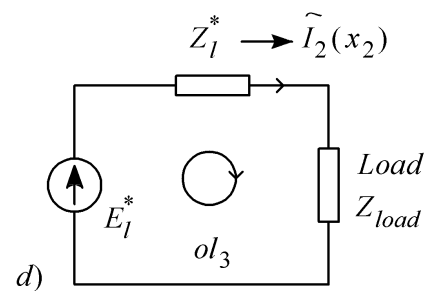

Fig.2. a) Voltages and currents at the input: $x=0, x=x, x=\ell$ along a homogeneous element of the air duct, b) Periodic function of the current of the transient process, c) T scheme of the circuit excited by the fundamental harmonic, d) Simplified circuit.

Symbolic-complex voltage transformation $v(x, t) \leftrightarrow \widehat{V}(x) e^{j w \cdot t}$ and current $i(x, t) \leftrightarrow \widehat{I}(x) e^{j w \cdot t}$ is:

$$
\begin{aligned}
& i(x, t) \Leftrightarrow \widehat{I}(x) \quad i_{1}\left(x_{1}, t\right) \Leftrightarrow \widehat{I}_{1} \quad i_{2}\left(x_{2}, t\right) \Leftrightarrow \widehat{I}_{2} \\
& v(x, t) \Leftrightarrow \widehat{V}(x) \quad v_{1}\left(x_{1}, t\right) \Leftrightarrow \widehat{V}_{1} \quad v_{2}\left(x_{2}, t\right) \Leftrightarrow \widehat{V}_{2}
\end{aligned}
$$

For the dominant harmonic of the voltage source $v_{v=1} \omega=1 \cdot 2 \pi \cdot f$ the complex transformations of the first derivations are:

$$
\begin{aligned}
\frac{\partial v}{\partial x} & \Leftrightarrow j \omega \cdot \widehat{V}(x)+(j \omega / \pi)[v(x, T)-v(x, 0)] \\
\frac{\partial i}{\partial x} & \Leftrightarrow j \omega \cdot \widehat{I}(x)+(j \omega / \pi)[i(x, T)-i(x, 0)]
\end{aligned}
$$

According to equations (20) and the convolution and translation theorems, the following system of equations can be written for $v=1$ harmonic:

$$
\begin{aligned}
& -\frac{\partial \hat{V}(x)}{\partial x}=(r+j \omega l) \widehat{I}(x)+\frac{j \omega \cdot l}{\pi}[i(x, T)-i(x, 0)], \\
& -\frac{\partial \hat{I}(x)}{\partial x}=(g+j \omega \cdot c) \widehat{I}(x)+\frac{j \omega \cdot c}{\pi}[v(x, T)-v(x, 0)]
\end{aligned}
$$

By integrating the system of equations (21) with defined boundary conditions from equations (18) at the inlet (index '1' $x=x_{1}=0$ and out index '2' $x=x_{2}=\ell$ and $x_{2}-x_{1}=\ell$ ) the voltage and current equations are obtained for the line with distributed parameters: 


$$
\begin{aligned}
& V_{1\left(x=x_{1}\right)}=V_{2\left(x=x_{2}\right)} \operatorname{ch}\left(\gamma \cdot x_{x=x_{2}}\right)+I_{2\left(x=x_{2}\right)} Z_{c} \operatorname{sh}\left(\gamma \cdot x_{x=x_{2}}\right)+\widehat{E}_{w} \\
& I_{1\left(x=x_{1}\right)}=\left(V_{2\left(x=x_{2}\right)} / Z_{c}\right) \operatorname{sh}\left(\gamma \cdot x_{\left(x=x_{2}\right)}\right)+I_{2\left(x=x_{2}\right)} \operatorname{ch}\left(\gamma \cdot x_{\left(x=x_{2}\right)}\right)+\widehat{J}_{v}
\end{aligned}
$$

According to equation (22) it means that homogeneous element-line of $x_{1}$ to $x_{2}$ suits the scheme T, Fig. 2.a:

$$
\begin{aligned}
& V_{1}=V_{2} \operatorname{ch}\left(\gamma \cdot h_{w}\right)+I_{2} Z_{c} \operatorname{sh}\left(\gamma \cdot h_{w}\right)+\widehat{E}_{w} \\
& I_{1}=\left(V_{2} / Z_{c}\right) \operatorname{sh}\left(\gamma \cdot h_{w}\right)+I_{2} \operatorname{ch}\left(\gamma \cdot h_{w}\right)+\widehat{J}_{v}
\end{aligned}
$$

Constant/coefficient of propagation of current and voltage wave and its complex value in geometric, exponential, vector/phasor and symbolic form [1,2] is:

$$
\begin{aligned}
& \gamma^{\bullet}=\sqrt{\hat{z} \cdot \hat{y}} \sqrt{(r+j \omega l)(g+j \omega c)} \\
& \gamma^{\bullet}=\gamma \cos \varepsilon+j \gamma \sin \varepsilon=\gamma \cdot e^{j \varepsilon}=\underline{\breve{\gamma} / \underline{\varepsilon}}=\beta+j \alpha
\end{aligned}
$$

Where $\beta$ is the realistic part (attenuation coefficient) $(\mathrm{Np} / \mathrm{km}), \alpha$ is the imaginary part (phase constant); if the angle is in arc measures $(\mathrm{rad} / \mathrm{km})$ then the speed at which the current or voltage wave propagates is the same:

$$
\begin{aligned}
& \gamma=\sqrt{(r+j \omega l)(g+j \omega c)}=\beta+j \alpha \\
& \gamma^{2}=\beta^{2}-\alpha^{2}+2 j \alpha \beta=r g-\omega^{2} l c+j \omega \cdot(g l+r c)
\end{aligned}
$$

The complex value is divided into the real and imaginary part and is:

$$
\begin{aligned}
& \beta^{2}-\alpha^{2}=r g-(v \omega)^{2} l c \quad 2 \alpha \beta=(v \omega)(g l-r c) \\
& \alpha=\sqrt{\left.-\frac{1}{2}\left[r g-(\omega)^{2} l c\right]+\frac{1}{2} \sqrt{\left[r^{2}+\omega^{2} l^{2}\left[g^{2}+\omega^{2} c^{2}\right.\right.}\right]} \\
& \beta=\sqrt{\frac{1}{2}\left[r g-\omega^{2} l c\right]+\frac{1}{2} \sqrt{\left[r^{2}+\omega^{2} l^{2}\right]\left[g^{2}+(v \omega)^{2} c^{2}\right]}} \\
& |\gamma|^{2}=(\beta+j \alpha) *(\beta-j \alpha)=\beta^{2}+\alpha^{2}=\sqrt{\left[r^{2}+\omega^{2} l_{l}^{2}\right]\left[g^{2}+\omega^{2} c^{2}\right]} \\
& z a \beta=0 \quad \gamma \cdot j \alpha=j \omega \sqrt{l_{l} \cdot c}
\end{aligned}
$$

Under this condition from equation (23), part $x_{2}-x_{1}$ suits $\mathrm{T}$ scheme $v=1$ harmonic where $Z_{1}=Z_{2}$, Fig. 2.c.

For $g \cong 0$ we get:

$$
\begin{aligned}
Z_{c} & =\sqrt{\left(r+j w l_{l}\right) / j w c} \quad \beta^{2}-\alpha^{2}=-(v \omega)^{2} l_{l} c \\
\gamma^{*} & =\sqrt{\hat{z} \cdot \hat{y}}=\sqrt{(r+j \omega l)(j \omega c)} \quad 2 \alpha \beta=(v \omega)(-r c)
\end{aligned}
$$

In a circuit with distributed parameters and an alternator, the parameters and magnitudes of the $T$ scheme are the impedance of the left branch $Z_{1}$, right branch impedance $Z_{2}$ and transverse branch impedance $Z_{3}$ respectively:

$$
\begin{aligned}
& Z_{1}=Z_{c} \cdot \operatorname{th} \frac{\gamma \cdot \ell}{2}=Z_{c} \cdot \operatorname{th} \frac{\gamma}{2}\left(x_{2}-x_{1}\right) \\
& Z_{2}=Z_{c} \cdot \operatorname{th} \frac{\gamma \cdot \ell}{2}=Z_{c} \cdot \operatorname{th} \frac{\gamma}{2}\left(x_{2}-x_{1}\right) \\
& Z_{3}=\frac{Z_{c}}{\operatorname{sh}(\gamma \cdot \ell)}=Z_{c} \frac{1}{\operatorname{sh} \gamma\left(x_{2}-x_{1}\right)}
\end{aligned}
$$

Also the values of the emf (electromotor force) of the left and right branches of the circuit are: 


$$
\begin{aligned}
& \widehat{E}=-Z_{c} \frac{\operatorname{ch} \gamma\left(x_{2}-x_{1}\right)}{\operatorname{sh} \gamma\left(x_{2}-x_{1}\right)} \widehat{J}_{w}+\widehat{E}_{w} \\
& \widehat{E}^{\prime}=-Z_{c} \widehat{J}_{w} \frac{1}{\operatorname{sh} \gamma\left(x_{2}-x_{1}\right)}
\end{aligned}
$$

To determine the currents and voltages at the end of the line $x=x_{2}=\ell$, scheme on Fig. 2.a can be tranformed in circuit as on Fig 2.d, sutable to expression $\widehat{V}_{2}=Z_{\text {Load }} \widehat{I}_{2}$ if applied I and II Kirhof law.

\section{Results and Discussions}

The presented method and the following simulation will enable fast and high-quality solving of processes that are important for relay protection and automatic control. Using experience in the simulation of single-phase equivalent electrical circuits related to circuit breakers, it is possible to successfully analyze the phenomena and evaluate the values of voltages and frequencies that occur in the process of atmospheric discharges.

Analytical considerations performed show the functional capabilities of the above-ground atmospheric discharge process model.

The system of previously derived equations is easily implemented in blocks provided by the MATLAB Simulink software package [19]. Model compiled for MATLAB Simulink software package allows simulation of transient overhead line process.

The parameters of the scheme elements are given in Fig. 3 (line-SCOPY1, Breaker-SCOPY2, Load-SCOPY3), and the simulation diagrams of currents and voltages in Fig. 4. A Fast Fourier transform is used in the simulation and the algorithm of transient processes.

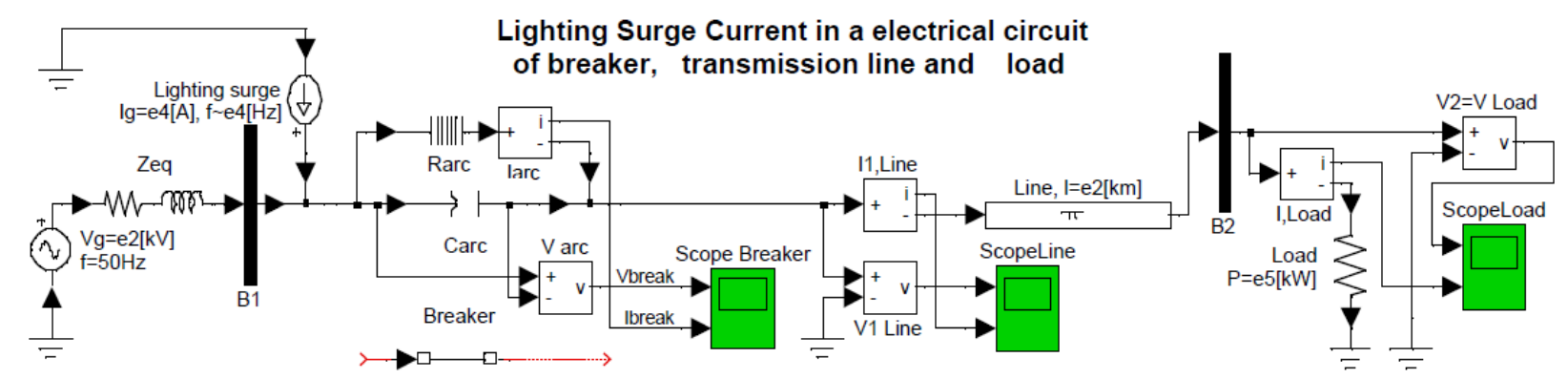

Fig.3. Model scheme for simulating the transient process in the electrical circuit of a switch.

For modification model and algorithmy served MATLAB program psbsurlightcurrent.mdl [19] and the scheme in Figs. 3 with the following parameters:

- Voltage source $10 \mathrm{kV}, 50 \mathrm{~Hz}$,

- Current source $I=33 \mathrm{kA}, f \cong 1 / 2 \pi \cdot T \cong 20 \mathrm{kHz}$,

- Equivalent impedance EES: $R_{1}=1,6 \Omega, L=11.5 e-3 \mathrm{H}$,

- Block parameters Arc in a Breaker: $R=0.0 \Omega, L=3 e-4 \mathrm{H}, C_{s}=1.4 e-7 \mathrm{~F}$,

- Block parameter VA characteristic in arc Breaker: $V_{r e f}=1.0 e 3 \mathrm{~V}, I_{\text {ref }}=80 \mathrm{~A}$, Seg.ch. $=0.955, k_{1}=50$, $\alpha_{1}=1.0, k_{2}=0.25, \alpha_{2}=0.99, k_{3}=16.5, \alpha_{3}=0.98$,

- Pi Section Line: $\ell=50 \mathrm{~km}, R_{1}=0.3508 \Omega, L_{1}=1.067 e-3 \mathrm{H} / \mathrm{km}, C_{1}=8.4 e-9 \mathrm{~F} / \mathrm{km}$,

- Load parameters: $V_{n}=10 e 3 \mathrm{~V}, f=50 \mathrm{~Hz}, P_{n}=500 e 3 \mathrm{~W}$. 


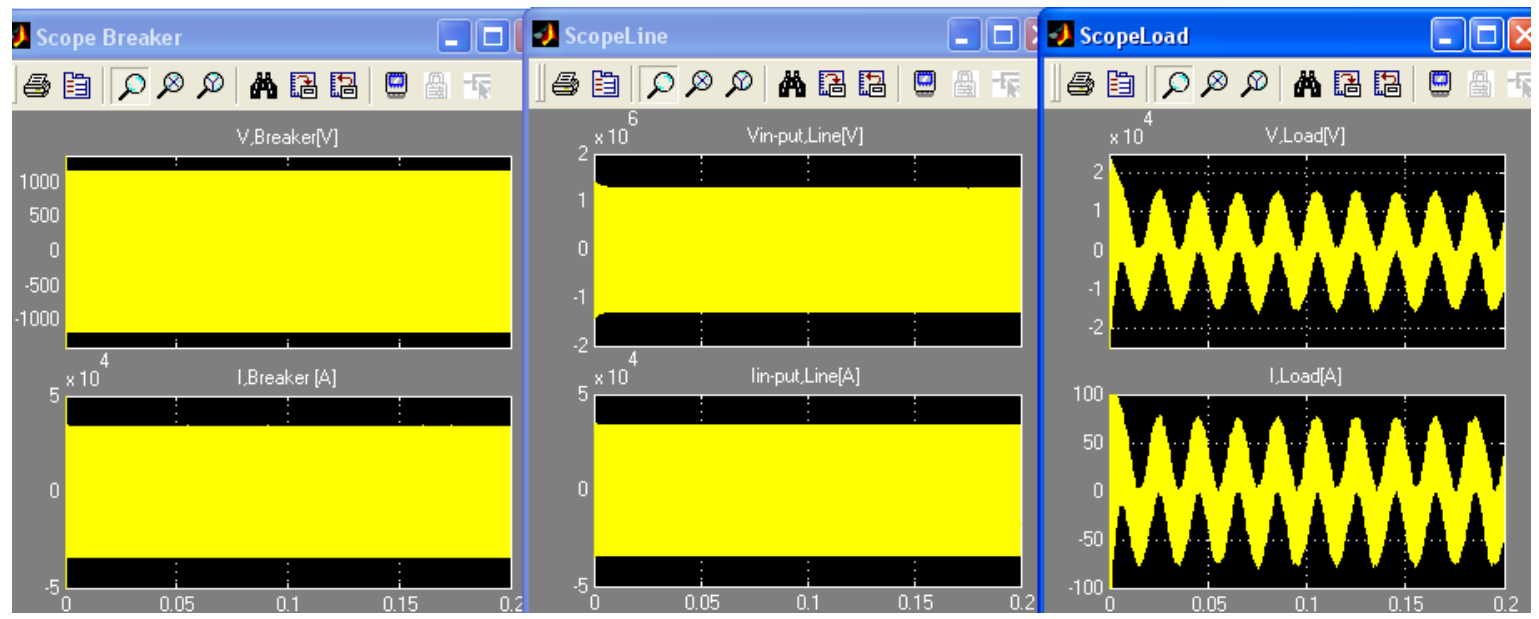

Fig.4. Comparison of diagram of current and voltage from Breaker, Pi Section Line, active load are connected with voltage source $V_{g}$ and Light Surge Current source $I_{g}$.

In the simulation, one can see what was observed in the classic way by measuring in an experiment.

An adapted part of the MATLAB software package was used to determine the voltage waveforms on the inductive load. This means that before measuring the overvoltage at the circuit breaker contacts, according to the described method, their values as well as their time course can be estimated. From the simulation diagram, it can be concluded how the process took place at each time point.

For prostoperiodic source voltage, the forms of voltage at the switch and the beginning of the line are indistinguishable. The voltage at the switch is due to the influence of the selected reference voltage level $(1 \mathrm{kV})$ electric arc (which yet is for $\approx 10^{3}$ time smaller than voltage for water value) for $\approx 10^{2}$ times the given source voltage at the load. It is interesting that at the load appear approximately the expected values of currents and voltages with a significant influence of harmonics, which in the operation of electrical receivers can be a great cause of interference, which will be discussed in some future work.

\section{Conclusions}

To create a model of transient processes, a basic analytical model is required that derives from the theory of the circuit from which the necessary knowledge is acquired. Analytically derived formulas, with simple conditions and assumptions, although they introduce some inaccuracies, provide an objective picture of the process. The model must adapt to new tendencies and knowledge, and the end result is some special model that presents real processes.

Solutions are more difficult to determine if only analytical methods are applied because, due to the presence of nonlinear elements, the procedures are based on simple conditions and assumptions and can introduce some inaccuracies. The problems in the analysis of atmospheric discharges accompanied by the appearance of ports can be minimized by the simulations presented. Changing any parameter in the circuit requires a new calculation of the circuit condition from the start due to the initial conditions. In this case, this is an example of a circuit with two sources: voltage-industrial frequency and current-high frequency. Circuit condition was determined using two methods, the operator and the superposition method. Atmospheric discharge is equivalent over current from a high-frequency current generator placed in front of a single-phase circuit breaker with distributed parameters that feeds the active load.

The model and algorithm shown are universal and can also be used for various conditions where a power line can be found. The MATLAB program has a threefold purpose: to serve the calculation and simulation of the quantities that can be obtained by testing or measuring, to establish the original algorithm and to verify the proposed method. The simulation can replace the type tests on the switch and the line. From the obtained results-diagrams of voltages and currents at the point of impact in the line, voltages and currents at the switch and voltages and currents at the load can be seen similarities and differences in shapes, as well as a sharp rise in values at the selected points in the scheme.

Analytical methods combined with the simulation method were used in the investigation of overvoltages and the occurrence of asymmetries and harmonics during the action of atmospheric overvoltages, and during the occurrence of an electric arc.

The active resistance in the electrical circuit dampens the oscillations but does not affect their character. To the obtained result, if it is of interest for obtaining exact values, a function related to the damping of oscillations can be added.

In order for this work not to be too extensive, in some of the following papers will be presented new results related to additional simulations with a number of parameters that affect the transient processes in the electric arc. 


\section{References}

[1] S. Bjelić, "Protection Techniques in Electrical Energy Networks", pp. 117-118, 2018.

[2] N. Marković, S. Bjelić, "Protection against dangerous effects electric current", Kvark, Kraljevo, 2018.

[3] N. Marković, S. Bjelić, U. Jakšić, Z. Bogićević, "Graphical Zero-sequence Cut-offs Method of Determining of Fault to Earth in Electrical Lines", $9^{\text {th }}$ Symposium on Neural Network Applications in Electrical Engineering, Faculty of Electrical Engineering, University of Belgrade, Serbia, Neurel 2008, pp. 73-76.

[4] B. Jovanović, S. Bjelić, N. Marković, "Transient Processes on the Elements of Underground Installations", Information Technology and Computer Science, IJITCS 2017, Vol. 9, No. 9, pp. 1-10, DOI: 10.5815/ijitcs.

[5] G.S. Gunter, "Electrical Installations Handbok", P. 2, Siemens, JohnWiley\&Sons, $2^{\text {nd }}$ enlarged edition, pp. 786-807, 1987.

[6] N. Marković, S. Bjelić, J. Živanić, U. Jakšić, "Numerical Simulation and Analytical Model of Electrical arc Impedance in the Transient Processes", PRZEGLADD ELEKTROTECHNICZNY, ISSN 0033-2097, R. 89 NR 2a/2013, pp. 113-117.

[7] S. Bjelić, N. Marković, Z. Bogićević, I. Bjelić, "Application of Cauchy (Lipschitz) Criterion for Obtaining Theoretical Models of Atmosphere Striking Overvoltages", Information Technology and Computer Science, IJITCS 2019, Vol. 11, No. 9, pp. 2030, DOI: 10.5815/ijitcs.2019.09.03.

[8] S.N. Bjelić, "Atmospheric and commutation overvoltages in electrical distribution networks", Kvark, Kraljevo, 2020

[9] C. Magono, "Thunderstorms", Elsevier Scientific Publishing Company, 335 Jan van Galenstraat, Amsterdam, The Netherlands. 1980.

[10] I.S. Bjelić, F.N. Marković, N.A. Marković, S.N. Bjelić, "Influence of Metal Pipes in the Environment on Designing the Underground Electrical Installations”, International Journal of Image, Graphics and Signal Processing, IJIGSP 2020, Vol. 12, No. 6, pp. 1-12, DOI: 10.5815/ijigsp.2020.06.01.

[11] A.A. Mahfouz, M.K. Mohammed, F.A. Salem, "Modeling, Simulation and Dynamics Analysis Issues of Electric Motor, for Mechatronics Applications, Using Different Approaches and Verification by MATLAB/Simulink", International Journal of Intelligent Systems and Applications, IJISA 2013, Vol. 5, No. 5, pp. 39-57, DOI: 10.5815/ijisa.2013.05.06.

[12] А.М. Залескии, “Основы теории электрических аппаратов”, Висшая школа, Москва, 1974.

[13] О.Б. Брон, “Потоки Плазме в электрической дуги аппаратовы”, Енергија, Лењинград, 1975.

[14] Э.М. Базелян, Е.М. Базељан, “Искровой разряд в воздухе”, Сибирское Отделение Академий наук СССР, Новосибирск, Наука, 1998.

[15] И.Н. Бронштейн, К.А. Семендяев, “Справочник по математике для инженеров и учащихся втузов”, Наука, Москва, 1980.

[16] Z. Bogićević, S. Bjelić, P. Spalević, E. Abularjas, I. Ali, "The Model of Oscillatory Transient Process when Commutating the Switches", 25. Electrotechnical and Computer Science Conference, ERK 2016, pp. 277-280.

[17] S. Bjelić, B. Jovanović, Z. Bogićević, N. Marković, I. Bjelić, "Theoretical Model of the Electric Field of Stray Currents in Underground Installations in Urban Environments", Bjast 2017, Review Article, Vol. 19, Issue 4, 2017/BJAST/31690.

[18] L. Van der Sluis, "Transients in Power Systems", John Wiley \& Sons Ltd, 2001.

[19] MATLAB SIMULINK Sim Power System, Copyright 1984-2002 The Math Works, Version 6.5.0,180913a, June 2, 2000.

\section{Authors' Profiles}

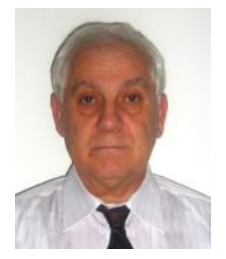

Slobodan N. Bjelić: Full-time professor at Faculty of Technical Sciences University in Pristina with temporarily seat seat in Kosovska Mitrovica. He received his Ph.D. degree in 1982, field of interest: Electrical EngineeringComputer Science-Protective Relays-Electrical Installation and Illumination Engineerings-Electrical Power Converters. He is author and co-author of 10 textbooks and over 200 scientific and professional papers published in international and Serbian journals.

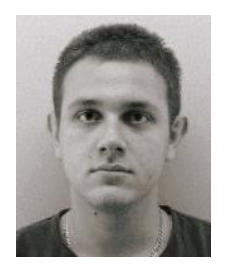

Filip N. Marković: Student on $4^{\text {rd }}$ year at Faculty of Technical Sciences-University in Pristina with temporarily seat in Kosovska Mitrovica. Field of interest: Electrical and Computer Engineering, Computer Engineering and Software Engineering. He is author and co-author of several papers in the field of electrical engineering and computer science published in national and international peer-reviewed journals.

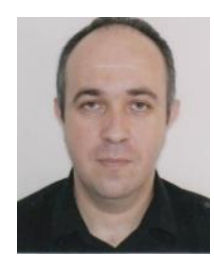

Nenad A. Marković: Professor at study programs Mechanical engineering and Road Traffic on High Technical School of Professional Studies Urosevac with temporarily seat in Leposavic. He is received his Ph.D. degree from Faculty of technical Sciences in Cacak-University of Kragujevac. Author and co-author is of many textbooks, exercises and over 125 papers published in international and Serbian journals. 
How to cite this paper: Slobodan N. Bjelić, Filip N. Marković, Nenad A. Marković, "Transient Process at Atmospheric Discharge into the Landline and the Appearance of an Electric Arc in the Switch", International Journal of Information Technology and Computer Science(IJITCS), Vol.13, No.2, pp.27-37, 2021. DOI: 10.5815/ijitcs.2021.02.03 